\title{
Team assessment behaviour (TAB): Is it an ideal tool for improving professional behaviour in trainee doctors
}

\author{
Syed Adnan Kabir ${ }^{1}$, Syed Irfan Kabir², Imran Khan ${ }^{3}$, Roma Patel ${ }^{4}$ \\ ${ }^{1}$ Surgical Department, Victoria Teaching Hospital, Glasgow, G42 9TY \\ ${ }^{2}$ Heatherwood and Wexham Park Hospital, Slough, Berkshire, SL22AL \\ ${ }^{3}$ Department of Otolaryngology, Victoria Teaching Hospital, Glasgow, G42 9TY \\ ${ }^{4}$ Department of Surgery, Lincoln County Hospital, Lincoln, U.K, LN25 QY \\ Email address: \\ Adnankabir58@hotmail.com (S. A. Kabir)
}

\section{To cite this article:}

Syed Adnan Kabir, Syed Irfan Kabir, Imran Khan, Roma Patel. Team Assessment Behaviour (TAB): Is it an Ideal Tool for Improving Professional Behaviour in Trainee Doctors. Journal of Surgery. Vol. 2, No. 5, 2014, pp. 78-81. doi: 10.11648/j.js.20140205.15

\begin{abstract}
The assessment of a trainee doctor's performance in a clinical setup is not only challenging and important, but is also necessary to assure standards, judge competence to practice, set targets for improvements, and most importantly to protect patients. Multi source feedback (MSF) / Mini-Pat (Mini Peer Assessment Tool) / Team Assessment Behavior (TAB) are formative assessment tools that were developed to assess the professional behaviors and attitudes in health professionals, and to continually improve an individual's team working skills. This article critically evaluates the use of Team Assessment Behavior (TAB) as an assessment tool for professional behavior in trainee doctors in the U.K, and concludes whether it is an ideal tool for improving professional behavior in trainee doctors.
\end{abstract}

Keywords: Team Assessment Behaviour, Mini Peer Assessment Tools, Formative Assessment Tools, Work Based Assessments, Professional Behaviour in Trainee Doctors

\section{Introduction}

The concept of evaluation of a doctor's professionalism in a clinical setup is a relatively new phenomenon that has gained a lot of momentum in recent years. It had been introduced to ensure the safety of the public following serious concerns about poorly performing doctors and also to improve their performance in a clinical set up. ${ }^{1}$

The General Medical Council (GMC) in the United Kingdom is the legal body, whose function under the medical act is 'to promote, protect and maintain the health and safety of the public by ensuring proper standards...' - In 1997 it produced its first report on performance related procedures, which stated that in addition to the assessment of competence to test knowledge and basic skills, the performance of doctors who enter the procedures should also be thought as well as assessed through peer review of practice in the workplace. $^{2}$

Ramsden ${ }^{3}$ states: "the student will learn what they think they will be assessed on, not what is in the curriculum, or even on what has been 'covered in class'....". Therefore, if the intention of the learning objective is to improve professional behavior and team working skills within trainee doctors, then we need to introduce an assessment method that not only assesses both the above mentioned characteristics, but it is also important that the tool in addition also provide feedback to its trainee's on how to improve their professional behavior at their work place.

Multi source feedback (MSF) / Mini-Pat (Mini Peer Assessment Tool) / Team Assessment Behavior (TAB) are formative assessment methods that were developed to assess the professional behaviors and attitudes in health professionals with an aim to continually improve an individual's team working skills.

This concept of assessment was initially developed by the industrial organization, and since the 1990's had been used in postgraduate medicine for the assessment of professional behavior of trainee doctors in the United States Of America (USA). It was recommended by Ramsey ${ }^{4}$ who proposed that it was feasible to obtain assessment from professionals associates of practicing physicians in areas such as clinical skills, humanistic qualities, and communication skills. ${ }^{5,6}$ 
In the U.K with the implementation of Modernizing Medical Careers the Postgraduate Medical Education Training Board (PMETB) embarked on formulating a mixed set of assessment tools for trainees in postgraduate training. ${ }^{7,8}$

It also accepted that medical practice should not only focus on scientific knowledge but other important parameters, such as communication skills, team working and humanistic qualities, too have significant effects on patient care and therefore should be taken into consideration, further more it also highlighted the importance of feedback from peers by a formal assessment tool that allowed comparison against those peers who were at the same level of training. Hence a formative assessment tool, mini -PAT (Peer Assessment Technique) was integrated as a requirement for good medical practice. $^{9}$

The main aim of MSF/ Mini-PAT / TAB is to identify trainees, whose professional conduct does not meet the GMC criteria of good medical practice, so that an appropriate action might be taken, and in addition complement those who receive good reports.

Usually 10-15 multi-disciplinary colleagues assess and rate the trainees workplace behavior, four domains are assessed: professional relationship with patients, communications, accessibility and team working.

It is the trainees' responsibility to distribute at least 15 Mini-Pat forms to peers of his or her choice, included a supervising consultant, at least three other doctors and at least five allied healthcare professionals, with a minimum requirement of 10 completed forms that are need to be returned in order to be validated.

It is the responsibility of the educational supervisor to collate and summarize these assessment forms, identify weaknesses, offer feedback and directed learning objectives, to any concerns that might have been arisen as a result of this practice.

\section{Validity and Reliability of Team Assessment Behavior (TAB)}

TAB portrays face as well as content validity as it assesses areas recognized by the $\mathrm{GMC}^{10}$ for good professional behavior, and is shown to be capable of identifying behavior related problems in trainees which was the main aim of this tool. $^{11}$

In addition, TAB also appears to have good construct validity as it tests a trainee's behavior in real life situations.

It is difficult to define the predictive validity of any assessment tool, more so in a formative assessment tool. The creators of TAB have not tested this for concurrent validity, which can be easily tested by using a different behavior assessment tool in addition to TAB for some of the trainees or peers taking part during field-testing for reliability and validity. A reliable instrument for a piece of research will provide similar information from similar respondents over a period of time. ${ }^{12}$

Whitehouse ${ }^{11}$ demonstrated in his pilot study that TAB had intra-observer reliability and inter-observer variability. For inter-observer variability, Royal College of Psychiatrists collected a map of assessment programs against good medical practice domains and considered it appropriate for assessing four domains i.e. good clinical care, working with peers, probity and health. ${ }^{13}$

\section{Raters}

Ramsey et $\mathrm{al}^{4}$ concluded that, for MSF, 10-11 respondents were necessary to achieve a coefficient of 0.70 , however Wood et $\mathrm{al}^{13}$ in their study on gynecology and obstetrics trainees concluded that 8 raters were sufficient for a representative score, more raters would lead to a better coefficient and more generalized results. TAB at present advocates at least 10 raters to achieve a reliable result.

\subsection{Feasibility}

TAB has 4 domains and a 3-point rating scale which can easily be understood, and be completed by their rates using the web-based online system, it requires no training and taken less than 5 minutes to complete, Hence reducing the cost of administrative resources when compared with a paper-based system.

\subsection{Trainer \& Trainees Evaluation of the Process}

Whitehouse et $\mathrm{al}^{11}$ as part of their field assessment on TAB concluded that both the assessors and trainers found the assessment process practical, valuable and fair.

Also $76 \%$ of the trainees considered $\mathrm{TAB}$ as an added useful tool for the assessment of the senior house officers (SHO's), however educational supervisors had mixed thoughts, with $77 \%$ of them finding out nothing more or new about their trainees than they would already know.

\subsection{Patient Outcomes}

Though the process of TAB in itself does not bear any direct consequences or outcome on patients overall clinical management, but can help the trainee improve his profession behavior, which is an important element of good medical practice as set out by the GMC.

An improvement in a doctor's behavior due to the appraisal-feedback process can indirectly improve and contribute to patient management and satisfaction. ${ }^{1,5}$

\subsection{Potential Barriers In TAB}

\section{Choice of Raters:}

In $\mathrm{TAB}$ except for the trainees supervising consultant, who must be involved in the process, the trainee has the freedom to choose his own raters.

This can be a potential area of complexity, as the trainee might pick up raters whom he/she might get along really well and may not include a peer whom they did not get along with, hence leading to biased results.

Similarly if there is a potential conflict between the supervising consultant and his trainee, than this conflict 
might lead to clouding of judgments ${ }^{14}$, these concerns can be addressed by having different assessors and supervising trainers, but unfortunately considering high service pressures on the NHS, this might not always be possible.

Feedback:

The value of the process of TAB can be restricted by the quality of feedback given to the trainees at the end of the assessment process and depends a lot on the relationship between the supervising consultant and the trainee, ${ }^{15}$

Evidence have shown that a feedback that is non-specific does little to change performance of a trainee, Whitehouse ${ }^{11}$ in their initial study concluded that TAB was able to produce a descriptive feedback that was more helpful and specific compared to the present MSF tools.

Assessors who are rating the TAB may not give specific feedback or comments however they are advised to give some information, mainly if they are to chose the ratings of "no concern", "some concern" or 'major concern'. Bret and Atwater ${ }^{16}$ have also shown that negative feedback cannot only discourage trainees but they can also react in anger.

Feedback on performance must be descriptive and specific if it is to be of constructive value to a trainee ${ }^{17}$. Therefore it is the main responsibility of the supervisor to give a constructive feedback, which is relevant and helpful, as well as creating an action plan with the trainee and to address any identified deficiencies. It must also be stressed that good performers need to be complimented, and encouraged to do so.

\subsection{Training the Raters and the Supervisor}

The raters, too need to be educated in this process otherwise they may not give reliable views about the trainee, ${ }^{7}$ also from the raters point of view, it would be very helpful if they were to give specific comments to the trainee whom they are rating so that a more relevant feedback can be provided.

Most importantly, the educational supervisors who provided the feedback to the trainee can make a difference by constructing an agreed learning objective, and not demoralizing the trainee with negative feedbacks, this view has also been supported by Kaplan ${ }^{18}$, who noted that negative feedback could de-motivate a trainee.

Giving face-to-face negative feedback can be an intimidating task and supervisors, if not properly trained in giving negative feedback might dislike doing it, as a result may not give a proper constructed feedback.

\section{Conclusions}

In the U.K, with the introduction of the European Working Time Directives (EWTD) in the National Health Services (NHS), the amount of time required to train a doctor had decreased quite significantly, as a result of poorly performing doctors and high patient expectations lead to an increasing demand for the development of a more efficient training structure in which supervised learning and training opportunities could be maximized.

Modernizing Medical Careers and the Postgraduate
Medical Education Training Board (PMETB) embarked on formulating a mixed set of assessment tools for trainees to improve their training.

The main aim of these assessments was to not only provide evidence on the trainee's ability but more importantly to improve the quality of workplace training.

Multi-source feedback, team assessment behavior, 360 degree feedback, peer review and peer ratings are different names given to the same process whereby a trainee receives formal feedback on his / her professional behavior at his workplace from peers and educational supervisors.

It has been suggested that this assessment process in itself does not bear any direct consequences or outcome on patients overall clinical management, but can help the trainee improve his profession behavior, which is an important element of good medical practice as set out by the GMC.

An improvement in a doctor's behavior due to the appraisal-feedback process can indirectly improve and contribute to patient management and satisfaction, provided both the raters and supervisors are trained in giving constructive feedback.

TAB if used correctly can serve its purpose both as a screening tool and also for the trainee to improve his professional behavior through reflection, which is achievable with further qualitative studies with an aim to explore potential barriers and experiences of trainees and how it can be overcome.

\section{References}

[1] Raven Department of education. Assessment of surgical trainees: Training the Trainers, Module 1: Learning and teaching (2006) page 44.

[2] Southgate L, Cox T, David T, et al. The General Medical Council's performance procedures: peer review of performance in the workplace. Med Educ. 2001; 35 (Suppl 1): 9-19

[3] Ramsden P. Learning to teach in higher education. 1992. London Routledge Press.

[4] Ramsey PG, Carline JD, Blank LL, Wenrich MD. Feasibility of hospital based use of peer ratings to evaluate the performances of practicing physicians. Academic Medicine 1996; $71: 364-70$.

[5] Milind Pant, Prabhu N Nesargikar, Daniel M Cocker. Team Assessment Behaviour as an assessment tool: A Critical Evaluation: BJMP 2009: 2 (3) 35-37.

[6] Woolliscroft J, Howell J, Patel BP, Swanson DB, Residentpatient interactions: The humanistic qualities of internal medicine residents assessed by patients, attending physicians, program supervisors and nurses. Academic Medicine 1994; 69 216-224.

[7] Southgate L, Grant J. Principles of an assessment system for postgraduate medical training. London: PMETB, 2004. A working paper from the Postgraduate Medical Education Training Board. 
[8] The Foundation Programme Committee of the Academy of Medical Royal Colleges, in co-operation with Modernising Medical Careers in the Departments of Health. Curriculum for the Foundation Years in Postgraduate Education and Training. London: Department of Health, 2005.

[9] Aza Abdulla. A critical analysis of mini peer assessment tool (mini-PAT): JR Soc Med. 2008 January; 101(1): 22-26.

[10] Good Medical Practice: General Medical council London (2011).

[11] Whitehouse A, Hassel A, Wood L, Wall D, Walzman, Campbell I. Development and reliability testing of TAB a form for 360 degree assessment of senior house officers' professional behavior, as specified by the GMC. Medical Teacher 2005; 27:252-8.

[12] Cohen L, Manion L (2000). Research Meathods in education: 2000: $5^{\text {th }}$ Edition: Routledge Press.

[13] Wood L, Wall D, Bullock A, Hassell A, Whitehouse A, Campbell I. " Team Observation": A six year study of the development and use of multi-source feedback (360 degree assessment) in obstetrics and gynaecology training in the U.K. Medical Teacher 2006; 28: 177-84.
[14] Kuzmits FE, Adams AJ, Sussman L, Raho LE. 360-feedback in health care management: a field study. The Health Care Manager 2004; $23: 321-8$.

[15] Nicol DJ, Macfarlane-dick D. Formative assessment and self -regulated learning: a model and seven principles of good feedback practice. Studies in higher education 2006; 31 : 199218.

[16] Bret and Atwater. The journal of applied Psychology 2001; $86 ; 930-42$.

[17] Adulla A. Acritical analysis of mini peer assessment tool (mini-PAT); J R Soc Med 2008; 101; 22-26.

[18] Kaplin R.360 degree feedback PLUS : boosting the power of co-worker ratings for executives. Human Resource Management 1993; $32: 299-314$. 